Working Paper 2010:15

Department of Economics

\title{
Dynamic cost-benefit analysis of large projects: The role of capital cost
}

Chuan-Zhong Li and Karl-Gustaf Löfgren 
Department of Economics

Uppsala University

P.O. Box 513

SE-751 20 Uppsala

Sweden

Fax: +46184711478
Working paper 2010:15

August 2010

ISSN 1653-6975

DYNAMIC COST-BENEFIT ANALYSIS OF LARGE PROJECTS: THE ROLE OF CAPITAL COST

Chuan-Zhong Li and KarL-Gustaf LöFgren

Papers in the Working Paper Series are published on internet in PDF formats.

Download from http://www.nek.uu.se or from S-WoPEC http://swopec.hhs.se/uunewp/ 


\title{
Dynamic cost-benefit analysis of large projects: The role of capital cost
}

\author{
Chuan-Zhong Li and Karl-Gustaf Löfgren*
}

May 26, 2010

\begin{abstract}
This paper derives a dynamic cost-benefit rule for evaluating large projects. We show that, in addition to the conventional income and consumer surplus measures, the rule also entails an extra term involving capital cost changes.

JEL: D6, D9, H4.

Keywords: cost-benefit rule; large project; and capital cost.
\end{abstract}

${ }^{*}$ Chuan-Zhong Li, Department of Economics, Uppsala University, and Karl-Guataf Löfgren, Department of Economics, Umeå University. The authors would like to thank an anonymous referee for valuable comments and suggestions. The usual disclaimer applies. 


\section{Introduction}

Structural transformations occur frequently in real life, such as the replacement of an old road passing through a large number of cities by a large-capacity freeway moving the heavy traffic away from the urban areas. National environmental policy may change by discrete increases in emission taxes of pollutants and decreases in taxes on labor. One intention of such a green tax reform is to create large changes in equilibrium prices. Every time a project is large enough to considerably affect the prices in an economy, the dynamic theory of cost-benefit analysis for a marginal variation (see Starrett, 1988; and Li and Löfgren, 2008) has to be modified. The general idea behind the necessary modification is not new as it dates back to the French economist Dupuit. However, a satisfactory theory in a growth theoretic context has not been available until recently.

A rigorous theory for dynamic welfare comparisons has been developed by Weitzman (2001) who shows that the difference in intertemporal welfare between two economies or two points in time of the same economy can be exactly measured by the difference in real national income plus a consumer surplus term. In addition, he mentions that the theory may also be used to conduct social cost-benefit analysis by comparing the welfare levels generated by "twin economies" with identical preferences and technology but different initial capital stocks. This paper explores this issue further. We show that while the theory is valid for this special case, the cost-benefit rule for a more general, dynamic project also entails an extra term reflecting the change in capital costs during the project period.

\section{Model setup and the generic cost-benefit rule}

We consider a multisector growth model with all consumption and investment goods taken into account. Let $\mathbf{C}=\left(C_{1}, C_{2}, \ldots, C_{m}\right)$ be a $m$-dimensional vector of consumption flows at time $t$, which is supposed to exhaust all possible goods and services relevant to social welfare in a first best setting. The utilitarian measure of intertemporal welfare at time $t=0$ can be expressed as

$$
W=\int_{0}^{\infty} U(\mathbf{C}(t)) \exp (-\theta t) d t
$$


where $U(\mathbf{C})$ is a given concave, non-decreasing, instantaneous utility function with continuous second order derivatives defined for $\mathbf{C} \geq 0$, and $\theta$ is the utility rate of discount. Let $\mathbf{K}=\left(K_{1}, K_{2}, \ldots, K_{n}\right)$ be a $n$-dimensional vector of capital goods, which is assumed to contain all types of capital goods in the economy including natural resources and human capital. Net investments are, by definition, the change in capital stocks, i.e. $I_{i}=\dot{K}_{i}, i=0,1, \ldots, n$, which, in vector form can be expressed as $\mathbf{I}=\dot{\mathbf{K}}$, given $\mathbf{K}(0)=\mathbf{K}_{0}>0$. At each point in time $t$, consumption $\mathbf{C}(t)$ and investment $\mathbf{I}(t)$ are allocated within the $(m+n)$-dimensional attainable-possibility set $S(\mathbf{K}(t) ; \alpha)$, conditional on a collection of "parameters", $\alpha$, (Drèze and Stern, 1987), where the set is assumed to be strictly convex. The parameter $\alpha$ may represent any premise that modifies the feasible set for consumption and investment allocations. The decision-maker is assumed to maximize the current-value Hamiltonian at each $t$, i.e. $H(t)=U(\mathbf{C}(t))+\mathbf{\Psi}(t) \mathbf{I}(t)$ with respect to $\{\mathbf{C}(t), \mathbf{I}(t)\}$ subject to the initial condition and the attainability set, where $\boldsymbol{\Psi}(t)$ is the $n$-dimensional vector of the utility prices of capital satisfying the no-arbitrage condition $\dot{\Psi}=\theta \Psi-\nabla H_{\mathbf{K}}$ along the optimal trajectory. Let $\{\mathbf{C}(\alpha, t), \mathbf{I}(\alpha, t), \mathbf{K}(\alpha, t)\}$ be the conditional optimum trajectory, then the maximized intertemporal welfare can be expressed as

$$
W(\alpha) \equiv \int_{0}^{\infty} U(\mathbf{C}(\alpha, t)) \exp (-\theta t) d t
$$

Now, consider a project $\Delta \alpha$ with a change in $\alpha$ from $a_{0}$ to $\alpha_{1}$ over a project period $t \in[0, T]$, for $T \geq 0$, which, if implemented, would result in changes in the stream of consumption both within and beyond the project period. The general cost-benefit rule can be stated as "If the project $\Delta \alpha$ leads to a positive change in the intertemporal welfare in (2) i.e.

$$
\Delta W=W\left(\alpha_{1}\right)-W\left(\alpha_{0}\right)=\int_{0}^{\infty}\left[U\left(\mathbf{C}\left(\alpha_{1}, t\right)\right)-U\left(\mathbf{C}\left(\alpha_{0}, t\right)\right)\right] \exp (-\theta t) d t>0
$$

the project is socially profitable; otherwise not".

\section{A new result}

Since the cost-benefit rule involves an integral over an infinite time horizon, the project would be rather difficult to evaluate in practice. By using the notion of 
social profit (Dixit et al., 1980), we show how to transform the rule to a finite time horizon version and then derive a new dynamic cost-benefit rule as an extension of Weitzman's twin economy parable. First, we consider a large project $\Delta \alpha$ as a sequence of marginal projects $d \alpha$ to motivate our use of differentials (Starrett, 1988). Let $\mathbf{C}_{a}(\alpha, t)=\partial \mathbf{C}(\alpha, t) / \partial \alpha, \mathbf{I}_{\alpha}(\alpha, t)=\partial \mathbf{I}(\alpha, t) / \partial \alpha$ and $\mathbf{K}_{\alpha}(\alpha, t)=\partial \mathbf{K}(\alpha, t) / \partial \alpha$ denote the changes caused by a marginal project $d \alpha$ within the project period $t \in[0, T]$. Then, its net social profit at time $t$ can be expressed as

$$
B(\alpha, t)=\boldsymbol{\Pi}(\alpha, t) \mathbf{C}_{\alpha}(\alpha, t)+\boldsymbol{\Psi}(\alpha, t) \mathbf{I}_{\alpha}(\alpha, t)+\boldsymbol{\Omega}(\alpha, t) \mathbf{K}_{\alpha}(\alpha, t)
$$

where $\boldsymbol{\Pi}(\alpha, t)=\nabla U[\mathbf{C}(\alpha, t)]$ is the utility price of consumption, $\boldsymbol{\Psi}(\alpha, t)$ that of investment, and $\boldsymbol{\Omega}(\alpha, t)=\dot{\boldsymbol{\Psi}}(\alpha, t)-\theta \mathbf{\Psi}(\alpha, t)$ the cost-of-holding capital. Following Asheim (2000) and Arrow et al. (2003), we can now re-express the welfare change in (3) in the following manner:

Lemma 1 The welfare effect due to changes in future consumption as in (3) is equivalent to the present discounted value of social profits within the project period i.e.

$$
\Delta W=\int_{0}^{T} \int_{\alpha_{0}}^{\alpha_{1}} B(\alpha, t) \exp (-\theta t) d \alpha d t
$$

Proof. Since $\left[\boldsymbol{\Psi}(\alpha, t) \mathbf{I}_{\alpha}(\alpha, t)+\boldsymbol{\Omega}(\alpha, t) \mathbf{K}_{\alpha}(\alpha, t)\right] \exp (-\theta t)=\frac{d\left[\boldsymbol{\Psi}(\alpha, t) \mathbf{K}_{\alpha}(\alpha, t) \exp (-\theta t)\right]}{d t}$, the welfare change in (5) can according to (4) be written as

$$
\begin{aligned}
\Delta W & =\int_{0}^{T} \int_{\alpha_{0}}^{\alpha_{1}} \nabla U(\mathbf{C}(\alpha, t)) \mathbf{C}_{\alpha}(\alpha, t) \exp (-\theta t) d \alpha d t \\
& +\int_{\alpha_{0}}^{\alpha_{1}}\left(\mathbf{\Psi}(\alpha, T) \mathbf{K}_{\alpha}(\alpha, T) \exp (-\theta T)-\mathbf{\Psi}(\alpha, 0) \mathbf{K}_{\alpha}(\alpha, 0)\right) d \alpha
\end{aligned}
$$

For given $\mathbf{K}(0)$, we have $\mathbf{K}_{\alpha}(\alpha, 0)=0$. By definition $\mathbf{\Psi}(\alpha, T)=\frac{\partial \hat{W}(\mathbf{K}(\alpha, T))}{\partial \mathbf{K}(\alpha, T)}$ for $\hat{W}(\mathbf{K}(\alpha, T))=\int_{T}^{\infty} U\left(\mathbf{C}^{*}(\alpha, t)\right) \exp (-\theta(t-T)) d t$ with $\mathbf{C}^{*}(\alpha, t)$ as the optimal consumption path for $t \in[T, \infty)$, conditional on an "initial" capital $\mathbf{K}(\alpha, T)$. Thus, the second line in (6) becomes

$$
\left[\hat{W}\left(\mathbf{K}\left(\alpha_{1}, T\right)\right)-\hat{W}\left(\mathbf{K}\left(\alpha_{0}, T\right)\right)\right] e^{-\theta T}=\int_{T}^{\infty}\left[U\left(\mathbf{C}^{*}\left(\alpha_{1}, t\right)\right)-U\left(\mathbf{C}^{*}\left(\alpha_{0}, t\right)\right)\right] e^{-\theta t} d t
$$


which together with the first line in (6) constitutes the welfare difference as in (3).

To arrive at a cost-benefit rule comparable to Starrett (1988, p236-237) and Weitzman (2001), we introduce the following lemma.

Lemma 2 The present discounted value of social profits in (5) is equivalent to

$$
\Delta W=\int_{0}^{T}[\Delta Y(t)+C S(t)-\kappa(t)] \exp (-\theta t) d t
$$

where $\Delta Y(t)=Y_{1}(t)-Y_{0}(t)$ with $Y_{i}(t)=\boldsymbol{\Pi}\left(\alpha_{i}, t\right) \mathbf{C}\left(\alpha_{i}, t\right)+\mathbf{\Psi}\left(\alpha_{i}, t\right) \mathbf{I}\left(\alpha_{i}, t\right)$ as the comprehensive income in situation $i=0,1 . C S(t)=\int_{\boldsymbol{\Pi}\left(\alpha_{1}, t\right)}^{\boldsymbol{\Pi}\left(\alpha_{0}, t\right)} \mathbf{D}(\boldsymbol{\Pi}) d \boldsymbol{\Pi}$ is the consumer surplus with $\mathbf{D}(\boldsymbol{\Pi}(\alpha, t))=\mathbf{C}(\alpha, t)$ as the (compensated) consumption demand system, and

$$
\kappa(t)=\theta \int_{\alpha_{0}}^{\alpha_{1}} \boldsymbol{\Psi}(\alpha, t) \mathbf{K}_{\alpha}(\alpha, t) d \alpha
$$

is the cost of capital reallocation at time $t$.

Proof. Integrating (5) by parts over $\alpha$ for the first two terms of $B(\alpha, t)$ gives

$$
\begin{aligned}
\Delta W & =\int_{0}^{T}\left[Y_{1}(t)-Y_{0}(t)+C S(t)\right] \exp (-\theta t) d t \\
& +\int_{0}^{T} \exp (-\theta t) \int_{\alpha_{0}}^{\alpha_{1}}\left[\boldsymbol{\Omega}(\alpha, t) \mathbf{K}_{\alpha}(\alpha, t)-\mathbf{\Psi}_{\alpha}(\alpha, t) \mathbf{I}(\alpha, t)\right] d \alpha d t
\end{aligned}
$$

Defining the inverse capital demand function by the vector $\tilde{\mathbf{D}}(\mathbf{K}(\alpha, t))=\mathbf{\Psi}(\alpha, t)$, and recalling that $\boldsymbol{\Omega}(\alpha, t)=\dot{\boldsymbol{\Psi}}(\alpha, \mathbf{t})-\theta \mathbf{\Psi}(\alpha, t)$ and $\dot{\mathbf{K}}=\mathbf{I}$. Then, the inner integral in the second line becomes

$$
-\kappa(t)=\int_{\alpha_{0}}^{\alpha_{1}}\left[\left(\mathbf{K}_{\alpha} \tilde{\mathbf{D}}_{\mathbf{K}} \dot{\mathbf{K}}-\theta \mathbf{\Psi} \mathbf{K}_{\alpha}-\dot{\mathbf{K}} \tilde{\mathbf{D}}_{\mathbf{K}} \mathbf{K}_{\alpha}\right] d \alpha=-\theta \int_{\alpha_{0}}^{\alpha_{1}} \boldsymbol{\Psi} \mathbf{K}_{\alpha} d \alpha\right.
$$

where $\tilde{\mathbf{D}}_{\mathbf{K}}$ is a symmetric matrix following Young's theorem such that the two scalars $\mathbf{K}_{\alpha} \tilde{\mathbf{D}}_{\mathbf{K}} \dot{\mathbf{K}}$ and $\dot{\mathbf{K}} \tilde{\mathbf{D}}_{\mathbf{K}} \mathbf{K}_{\alpha}$ are equal to each other. Note that the arguments $\alpha$ and $t$ are suppressed here. Thus (8) is true.

These two lemmas imply the following main proposition: 
Proposition 1 Consider a project $\Delta \alpha$ over a time period $[0, T], T \geq 0$, which, if implemented, would result in changes in income $\Delta Y(t)$, consumer surplus $C S(t)$, and capital reallocation cost $\kappa(t)$ for each $t \in[0, T]$. Suppose that the welfare difference in (8) involving these variables is positive, then the project is socially profitable; otherwise not.

This dynamic cost-benefit rule extends Weitzman's (2001) "twin-economy" parable in two aspects. First, it is applicable to projects of structural reforms over any discrete time period rather than an once-for-all reshuffle in the initial capital. While Weitzman considers the welfare difference between two economies with different initial capital structure, we are concerned with an economy with a given initial capital but "managed" by two different regimes. If an alternative regime would result in a higher intertemporal welfare than the base one, then it is worth the effort to shift from the base regime to the alternative one. Second, we obtain an extra term $\kappa(t)$ reflecting the cost of capital reallocation in addition to the income difference and consumer surplus terms. Weitzman's comparison of twin economies can in our framework be interpreted as a project that can costlessly and instantaneously transform the initial capital composition. His reason is sound since the cost of the transformation is "sunk cost". We explicitly take into account the cost of capital reallocation. More exactly, by treating Weitzman's parable as a permanent project over $t \in[0, \infty)$, with $\lim _{T \rightarrow \infty} \exp (-\theta T)=0$, we can use (10) to derive the following version of our formula

$$
\begin{aligned}
\Delta W & =\int_{0}^{\infty} \int_{\alpha_{0}}^{\alpha_{1}} \Pi(\mathbf{C}(\alpha, t)) \mathbf{C}_{\alpha}(\alpha, t) \exp (-\theta t) d \alpha d t-\int_{\alpha_{0}}^{\alpha_{1}} \boldsymbol{\Psi}(\alpha, 0) \mathbf{K}_{\alpha}(\alpha, 0) d \alpha \\
& =\frac{\Delta Y(0)+C S(0)}{\theta}-\int_{\alpha_{0}}^{\alpha_{1}} \boldsymbol{\Psi}(\alpha, 0) \mathbf{K}_{\alpha}(\alpha, 0) d \alpha
\end{aligned}
$$

as $\Delta Y(0)+C S(0) \equiv \Delta H(0)=\theta \int_{0}^{\infty} \int_{\alpha_{0}}^{\alpha_{1}} \nabla U(\mathbf{C}) \mathbf{C}_{\alpha} e^{-\theta t} d \alpha d t$ is the well-known stationary equivalent change of future welfare. Multiplying both hand-sides of (12) by $\theta$, we obtain $\theta \Delta W=\Delta Y(0)+C S(0)-\kappa(0)$ where $\kappa(0)$ was assumed to be zero in Weitzman (2001). The relationship between our model and Starrett (1988) is less subtle, since he studies a discrete static project without any change in capital stocks. 
For a project extended over $t \in[0, T]$, we have to calculate the net benefit $\Delta Y(t)+C S(t)-\kappa(t)$ for each $t$, and then calculate the present value of this stream over $t \in[0, T]$ to assess the overall welfare effect.

\section{A money-metric analogy}

To convert the welfare measure in (8) from utility to a money metric, we first define the nominal prices by $\mathbf{P}(\alpha, t)=\boldsymbol{\Pi}(\alpha, t) / \lambda(\alpha, t)$ and $\mathbf{Q}(\alpha, t)=\boldsymbol{\Psi}(\alpha, t) / \lambda(\alpha, t)$, where $\lambda(\alpha, t)$ is the marginal utility of income satisfying the no-arbitrage condition $\dot{\lambda}(\alpha, t)=\lambda(\alpha, t)(r(\alpha, t)-\theta)$ with $r(\alpha, t)$ as the nominal interest rate. Next, we define the real prices by $\overline{\mathbf{P}}(\alpha, t)=\mathbf{P}(\alpha, t) / \pi(\alpha, t)$ and $\overline{\mathbf{Q}}(\alpha, t)=\mathbf{Q}(\alpha, t) / \pi(\alpha, t)$ with $\pi(\alpha, t)$ as Weitzman's ideal consumer price index

$$
\pi(\alpha, t)=\frac{\tilde{\mathbf{P}}(\alpha, t) \mathbf{C}\left(\alpha_{0}, t\right)}{\mathbf{P}\left(\alpha_{0}, t\right) \mathbf{C}\left(\alpha_{0}, t\right)}
$$

where $\tilde{\mathbf{P}}(\alpha, t)$ denotes the market clearing prices conditional on $\alpha$, for consuming the pre-project bundle $\mathbf{C}\left(\alpha_{0}, t\right)$. By the assumption of an invariant utility function $U(\mathbf{C})$, we have $\nabla U\left(\mathbf{C}\left(\alpha_{0}, t\right)\right)=\lambda\left(\alpha_{0}, t\right) \mathbf{P}\left(\alpha_{0}, t\right)=\lambda(\alpha, t) \tilde{\mathbf{P}}(\alpha, t)=\nabla U(\mathbf{C}(\alpha, t))$, for all $\mathbf{C}(\alpha, t)=\mathbf{C}\left(\alpha_{0}, t\right)$, which implies that $\pi(\alpha, t) \lambda(\alpha, t)=\lambda\left(\alpha_{0}, t\right)$. In present value terms, this last equality becomes $\pi(\alpha, t) \lambda(\alpha, t) \exp (-\theta t)=\lambda\left(\alpha_{0}, t\right) \exp (-\theta t)=$ $\lambda\left(\alpha_{0}, 0\right) \exp \left(-\int_{0}^{t} \bar{r}(s) d s\right)$ due to the no-arbitrage condition, where $\bar{r}(t)=r\left(\alpha_{0}, t\right)-$ $\dot{\pi}\left(\alpha_{0}, t\right) / \pi\left(\alpha_{0}, t\right)$ is the pre-project real interest rate at time $t$. Thus, the moneymetric welfare change corresponding to (8) can be expressed as

$$
\frac{\Delta W}{\lambda\left(\alpha_{0}, 0\right)}=\int_{0}^{T}[\Delta \bar{Y}(t)+\overline{C S}(t)-\bar{\kappa}(t)] \exp \left(-\int_{0}^{t} \bar{r}(s) d s\right) d t
$$

where $\Delta \bar{Y}(t)=\bar{Y}_{2}(t)-\bar{Y}_{1}(t)$ with $\bar{Y}_{i}(t)=\overline{\mathbf{P}}\left(\alpha_{i}, t\right) \mathbf{C}\left(\alpha_{i}, t\right)+\overline{\mathbf{Q}}\left(\alpha_{i}, t\right) \mathbf{I}\left(\alpha_{i}, t\right)$ as the comprehensive income in situation $i=0,1, \overline{C S}(t)=\int_{\overline{\mathbf{P}}\left(\alpha_{1}, t\right)}^{\overline{\mathbf{P}}\left(\alpha_{0}, t\right)} \mathbf{D}(\overline{\mathbf{P}}) d \overline{\mathbf{P}}$ the consumer surplus, and $\bar{\kappa}(t)=\bar{r}(t) \int_{\alpha_{0}}^{\alpha_{1}} \overline{\mathbf{Q}}(\alpha, t) \mathbf{K}_{\alpha}(\alpha, t) d \alpha$ the cost of capital reallocation, all in real terms ${ }^{1}$.

\footnotetext{
${ }^{1} \mathrm{~A}$ usual practice in cost-benefit analysis is to assume a constant marginal utility of income. However, Starrett (1988) shows that this is in general not consistent with utilitarian theory.
} 


\section{Conclusion}

This paper has derived a dynamic cost-benefit rule for large projects from a multisector growth model, conditionally optimal for a given collection of parameters. As in Drèze and Stern (1987), we define a project as the change in the parameter in a given time period, involving changes in consumption, investment and capital stocks over time. By examining the change in the present value of net social profits, we find that the dynamic cost-benefit rule entails an extra term involving the cost of capital reallocation, in addition to the conventional income plus consumer surplus terms in Weitzman (2001). This cost component should be relevant for any large investment project that accumulates capital over time.

\section{References}

Arrow, K. J., Dasgupta, P. and Mäler, K. G. (2003) Evaluating projects and assessing sustainable development in imperfect economies, Environmental and Resource Economics 26, 647-685.

Asheim, G. B. (2000) Green National Accounting: Why and How? Environment and Development Economics 5, 25-48.

Dixit, A., P. Hammond, M. Hoel (1980) On Hartwick's rule for regular maximin paths of capital accumulation and resource depletion, Review of Economic Studies 47, 551-556.

Drèze, J. and Stern, N. (1987) The theory of cost-benefit analysis, in Auerbach, A.J., Feldstein, M. (eds) Handbook of Public Economics vol. 2, Amsterdam: North Holland.

Li C. Z. and Löfgren, K. G. (2008) Evaluating projects in a dynamic economy: some new envelope results, German Economic Review 9, 1-16..

Starrett, D., (1988) Foundations of Public Economics, Cambridge: Cambridge University Press.

Weitzman, M. L., (2001) A Contribution to the theory of welfare accounting, Scandinavian Journal of Economics 103, 1-24. 
WORKING PAPERS*

Editor: Nils Gottfries

2009:6 Håkan Selin, Marginal tax rates and tax-favoured pension savings of the selfemployed Evidence from Sweden. 32pp.

2009:7 Tobias Lindhe and Jan Södersten, Dividend taxation, share repurchases and the equity trap. 27pp.

2009:8 Che-Yuan Liang, Nonparametric Structural Estimation of Labor Supply in the Presence of Censoring. 48pp.

2009:9 Bertil Holmlund, Incentives in Business and Academia. 12pp.

2009:10 Jakob Winstrand, The Effects of a Refinery on Property Values - The Case of Sweden. 27pp.

2009:11 Ranjula Bali Swain and Adel Varghese, The Impact of Skill Development and Human Capital Training on Self Help Groups. 28pp.

2009:12 Mikael Elinder. Correcting Mistakes: Cognitive Dissonance and Political Attitudes in Sweden and the United States. 25 pp.

2009:13 Sören Blomquist, Vidar Christiansen and Luca Micheletto: Public Provision of Private Goods and Nondistortionary Marginal Tax Rates: Some further Results. 41pp.

2009:14 Mattias Nordin, The effect of information on voting behavior. 34pp.

2009:15 Anders Klevmarken, Olle Grünewald and Henrik Allansson, A new consumer price index that incorporates housing. $27 \mathrm{pp}$.

2009:16 Heléne L. Nilsson, How Local are Local Governments? Heterogeneous Effects of Intergovernmental Grants. 41pp.

2009:17 Olof Åslund, Per-Anders Edin, Peter Fredriksson and Hans Grönqvist, Peers, neighborhoods and immigrant student achievement - evidence from a placement policy. $27 \mathrm{pp}$.

2009:18 Yunus Aksoy, Henrique S. Basso and Javier Coto-Martinez, Lending Relationships and Monetary Policy. 42 pp.

2009:19 Johan Söderberg, Non-uniform staggered prices and output persistence. $38 \mathrm{pp}$.

2010:1 Jonathan Gemus, College Achievement and Earnings. 43 pp.

2010:2 Susanne Ek and Bertil Holmlund, Family Job Search, Wage Bargaining, and Optimal Unemployment Insurance. 30 pp.

\footnotetext{
* A list of papers in this series from earlier years will be sent on request by the department.
} 
2010:3 Sören Blomquist and Laurent Simula, Marginal Deadweight Loss when the Income Tax is Nonlinear. 21 pp.

2010:4 Niklas Bengtsson, The marginal propensity to earn, consume and save out of unearned income in South Africa. 34 pp.

2010:5 Marcus Eliason and Henry Ohlsson, Timing of death and the repeal of the Swedish inheritance tax. 29 pp.

2010:6 Teodora Borota, Innovation and Imitation in a Model of North-South Trade. $44 \mathrm{pp}$.

2010:7 Cristiana Benedetti Fasil and Teodora Borota, World Trade Patterns and Prices: The Role of Productivity and Quality Heterogeneity. 24 pp.

2010:8 Johanna Rickne, Gender, Wages and Social Security in China’s Industrial Sector. 48 pp.

2010:9 Ulrika Vikman, Does Providing Childcare to Unemployed Affect Unemployment Duration? 43 pp.

2010:10 Sara Pinoli, Rational Expectations and the Puzzling No-Effect of the Minimum Wage. 56 pp.

2010:11 Anna Persson and Ulrika Vikman, Dynamic effects of mandatory activation of welfare participants. $37 \mathrm{pp}$.

2010:12 Per Engström, Bling Bling Taxation and the Fiscal Virtues of Hip Hop. $12 \mathrm{pp}$.

2010:13 Niclas Berggren and Mikael Elinder, Is tolerance good or bad for growth? $34 \mathrm{pp}$.

2010:14 Magnus Gustavsson and Pär Österholm, Labor-Force Participation Rates and the Informational Value of Unemployment Rates: Evidence from Disaggregated US Data. 10 pp.

2010:15 Chuan-Zhong Li and Karl-Gustaf Löfgren, Dynamic cost-bene $t$ analysis of large projects: The role of capital cost. 8 pp.

See also working papers published by the Office of Labour Market Policy Evaluation http://www.ifau.se/

ISSN 1653-6975 